\title{
A Comparison of Selected Parametric and Non-Parametric Imputation Methods for Estimating Forest Biomass and Basal Area
}

\author{
Donald Gagliasso ${ }^{1}$, Susan Hummel ${ }^{2}$, Hailemariam Temesgen ${ }^{1}$ \\ ${ }^{1}$ Department of Forest Engineering, Resources and Management, Oregon State University, Corvallis, USA \\ ${ }^{2}$ USDA Forest Service, Goods, Services, and Values Program, Portland Forest Sciences Laboratory, US Forest \\ Service, Pacific Northwest Research Station, Portland, USA \\ Email: dgagliasso@masonbruce.com
}

Received October $19^{\text {th }}$, 2013; revised November 21 $1^{\text {st }}$, 2013; accepted December $23^{\text {rd }}, 2013$

Copyright (C) 2014 Donald Gagliasso et al. This is an open access article distributed under the Creative Commons Attribution License, which permits unrestricted use, distribution, and reproduction in any medium, provided the original work is properly cited. In accordance of the Creative Commons Attribution License all Copyrights (C) 2014 are reserved for SCIRP and the owner of the intellectual property Donald Gagliasso et al. All Copyright (C 2014 are guarded by law and by SCIRP as a guardian.

\begin{abstract}
Various methods have been used to estimate the amount of above ground forest biomass across landscapes and to create biomass maps for specific stands or pixels across ownership or project areas. Without an accurate estimation method, land managers might end up with incorrect biomass estimate maps, which could lead them to make poorer decisions in their future management plans. The goal of this study was to compare various imputation methods to predict forest biomass and basal area, at a project planning scale $(<20,000$ acres) on the Malheur National Forest, located in eastern Oregon, USA. We examined the predictive performance of linear regression, geographic weighted regression (GWR), gradient nearest neighbor (GNN), most similar neighbor (MSN), random forest imputation, and k-nearest neighbor (k-nn) to estimate biomass (tons/acre) and basal area (sq. feet per acre) across 19,000 acres on the Malheur National Forest. To test the different methods, a combination of ground inventory plots, light detection and ranging (LiDAR) data, satellite imagery, and climate data was analyzed, and their root mean square error (RMSE) and bias were calculated. Results indicate that for biomass prediction, the $\mathrm{k}-\mathrm{nn}(\mathrm{k}=5)$ had the lowest RMSE and least amount of bias. The second most accurate method consisted of the k-nn $(k=3)$, followed by the GWR model, and the random forest imputation. For basal area prediction, the GWR model had the lowest RMSE and least amount of bias. The second most accurate method was $k-n n(k=5)$, followed by $k-n n(k=3)$, and the random forest method. For both metrics, the GNN method was the least accurate based on the ranking of RMSE and bias.
\end{abstract}

Keywords: Gradient Nearest Neighbor; Most Similar Neighbor; K-Nearest Neighbor; Random Forest; Geographic Weighted Regression; Biomass; LiDAR

\section{Introduction}

Estimates of forest biomass and basal area provide critical information for quantifying the amount of carbon sequestrated, making management decisions, designing processing plants, guiding decisions among conflicting land uses, and establishing and quantifying wildlife habitats. To meet national and international negotiations and reporting requirements, forest management plans require local inventory data on biomass, vegetation, site productivity, carbon, and other resources. The data must be intensive enough to include structural variables relevant to biomass and carbon projections and extensive enough to cover hundreds to thousands of acres, but not be too expensive to collect.

Recognition of the widespread need for cost-effective, local inventory data that spans large regions has led to new methods for imputing plot data to sites without data and then generating maps of regional biomass and productivity. One imputation method is the Gradient Nearest Neighbor (GNN). Vegetation maps created using GNN now figure prominently into interagency (Oregon Department of Forestry, USDI Bureau of Land Management, and USDA Forest Service) analysis and planning efforts across the Pacific Northwest. In addition, they are being used to estimate the supply of woody biomass available to proposed energy facilities and in regional conservation planning. Other techniques that use imputation, including K-NN (kNearest Neighbor), are used in parts of the Pacific Northwest. Both GNN and K-NN are used to derive forest biomass and basal area maps. For example, one can combine satellite imagery with data from field plots and impute a raster dataset showing a continuous map of biomass and basal area across the landscape (Ohmann \& Gregory, 2002).

GNN maps are created by using a multivariate model that integrates field plot data with satellite imagery and current mapped environmental data. GNN uses the nearest neighbor, or shortest distance, from a point to the nearest plot in predictor space to generate volume and basal area estimates that are then 
related to a specific timber type. The distance is measured by creating a weight matrix derived by canonical correspondence analysis (Ohmann \& Gregory, 2002). Similarly, MSN maps are created using a model that also integrates field plot data with satellite imagery. In contrast, MSN uses a canonical correlation analysis to derive a similarity function, with selected response variables, to impute data to pixels where no ground plots exist (Moeur \& Stage, 1995). The k-MSN method uses the same methods as MSN, but takes an average of the k nearest neighbor of plots. The Random Forest (RF) imputation method creates a classification matrix and regression tree in order to find similarities between the explanatory and response variables (Crookston \& Finley, 2008).

Nearest neighbor imputations have been used to perform multivariate analyses of forested landscapes by associating variables of interest (e.g. ground data) to aerial data (Temesgen et al., 2003), satellite imagery (Eskelson et al., 2009a), and light detection and ranging (LiDAR) data (Hudak et al., 2008; Goerndt et al., 2010). Different analyses have ranked the methods and data sources differently in different forest types. For example, in north-central Idaho, Hudak et al. (2008) found that the RF method performed best at predicting plot level estimates such as basal area and tree density. In Finland, Maltamo et al. (2006) compared k-MSN imputations for plot and stand level volume estimates and found that aerial-laser scanner data resulted in better estimates than using aerial photo imagery estimates and, when laser and photo data were used together, the resulting root mean square error improved again. Eskelson et al. (2009a) found that the RF method performed best when compared to the moving average, weighted moving average, and MSN and GNN imputation methods.

Parametric methods are an alternative to the nearest neighbor imputation methods that can be used to estimate selected variables of interest (Fotheringham et al., 2002; Wang et al., 2005; Salas et al., 2010; Crow \& Schlaegel, 1988). Linear and nonlinear models have been used for this purpose in previous studies (Wang et al., 2005; Nelson et al., 2004). Another option is geographic weighted regression (GWR), which takes a global regression model and localizes it to a specific area and allows relationships between the explanatory and response variables to account for spatial variations, by including a weighting function in the regression model Fotheringham et al. (2002).

Wang et al. (2005) developed an ordinary least squares (OLS) model, a spatial lag model, and a GWR model to analyze the amount of net primary production (NPP) in forest ecosystems across China. They used predictor variables that included forest stand locations, forest inventory data, and remotely sensed data. The authors found that the GWR model was superior to both the OLS model and the spatial lag model in predicting NPP.

Salas et al. (2010) modeled tree diameter using forest inventory and ancillary data. The models that the authors compared were OLS, generalized least squares (GLS), GWR, and linear mixed effects (LME). The authors used aerial LiDAR data and forest inventory plots to estimate diameter at breast height on individual trees in Norway. They found that the most precise approach was LME and GWR performed better than both the OLS and GLS.

\section{Airborne LiDAR Scanner (ALS)}

When current field inventory data are insufficient to achieve desired precision, a common practice is to increase the number of ground plots to measure the forest inventory. This can be costly and time-consuming. A newer practice would be to use LiDAR data. LiDAR is a tool that forestry researchers and professionals are increasingly using to improve estimates of forest inventory attributes; the cost may be comparable to traditional ground inventory data collection (Hummel et al., 2011).

LiDAR data are becoming a useful tool in obtaining large amounts of forest inventory data due to its precision and relative ease of ground truthing. Ground truthing LiDAR data consist of randomly locating plots across the landscape, measuring the trees on the plot, and georeferencing the trees so that they can be located in the LidAR data set for crown delineation (Wulder et al., 2008). LiDAR datasets can be used to describe large areas of forested landscape at one time.

Nelson et al. (2004) used LiDAR to estimate the amount of biomass and carbon in the state of Delaware. The authors used parallel flight lines 4 kilometers apart to measure the merchantable forest volume, biomass and above ground carbon. Using four explicitly linear models the authors predicted merchantable forest volume and above ground biomass across the state. The authors found that merchantable volume estimates were within $22 \%$ of US Forest Service (USDA FS) estimates county wide and $15 \%$ statewide. Additionally, the authors found that their biomass estimates were within $22 \%$ of USDA FS estimates county wide and $20 \%$ statewide. The USDA FS estimates were based on FIA volume and biomass estimates at the county and state level.

Næsset (2004) reported on the first Nordic stand-based forest inventory using LiDAR. The author predicted six stand variables from LiDAR data: mean tree height, dominant height, mean diameter, basal area, stem volume and stem number. Plot and tree level data were collected, including tree diameter at breast height (dbh), and tree height. With the plot data the author calculated: mean height, dominant height, mean diameter by basal area, plot basal area, number of trees per hectare, and total plot volume. The author found that $85 \%$ - $95 \%$ of the variability was explained by the regression models for mean height and dominant height. Additionally, $72 \%$ - 85\% of the variability was explained by the regression models for basal area and stand volume and $49 \%$ - $63 \%$ of the variability was explained by the regression models for mean diameter and stem number. Validation of the models revealed the mean differences between the ground truth data and the predicted values were statistically significant in 5 of 24 cases.

In this article, we examine the performance of four parametric and two non-parametric methods for estimating the amount of standing tree biomass and basal area at a pixel level, across the a site on the Malheur National Forest, in Eastern Oregon, US: Gradient Nearest Neighbor (GNN), Most Similar Neighbor (MSN), k-MSN, and the Random Forest (RF) nearest neighbor methods, and linear regression and geographic weighted regression. The different methods were assessed for their accuracy by comparing measured ground plot values to model estimates.

\section{Materials and Methods}

\section{Project Site}

The project site consists of 19,904 acres on the Malheur National Forest, located in the Blue Mountains of eastern Oregon (Figure 1), called the Damon project site. 


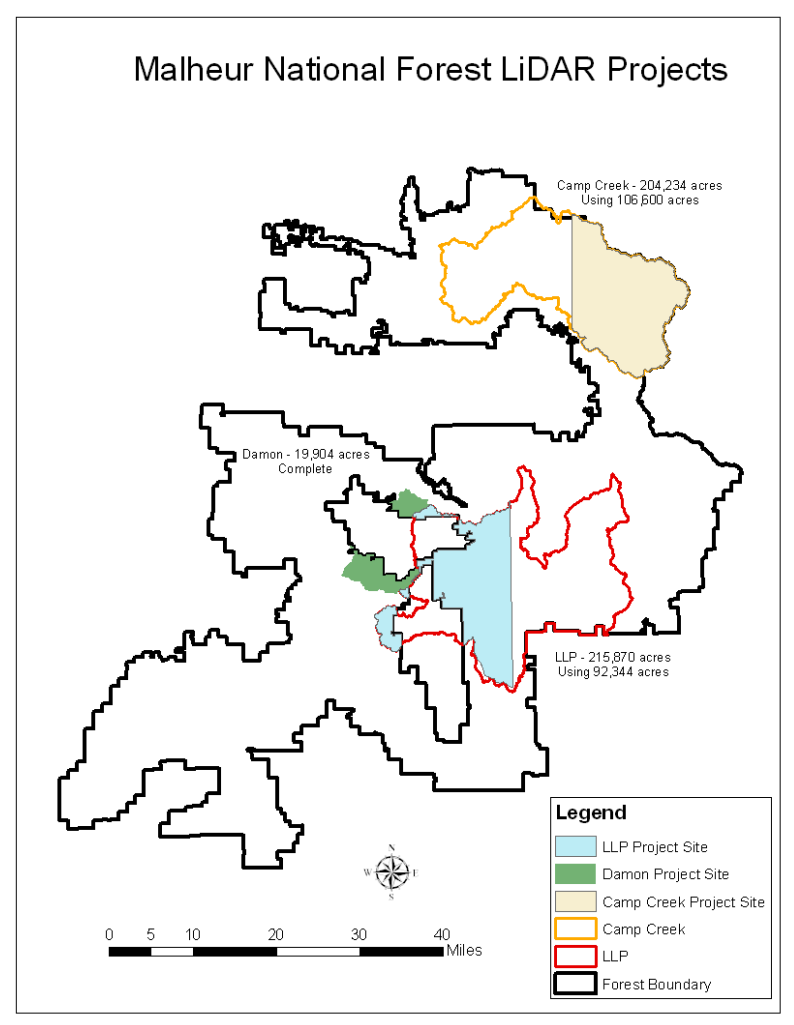

Figure 1.

LiDAR datasets on the Malheur National Forest.

\section{Airborne LiDAR Scanner}

The LiDAR data were collected during the fall of 2007 by Watershed Sciences, Inc. The LiDAR was acquired with a Leica ALS50 Phase II device mounted on a Cessna Caravan 208B. The scan angle was $\pm 14^{\circ}$ from nadir with an intended pulse density of $\geq 4$ pulse per square meter. The Leica ALS50 Phase II laser system is designed for up to four returns per pulse, and all laser returns were processed for the dataset. The actual pulse density was 6 pulses per square meter for the Damon site.

\section{Ground Data}

We had field data from three sources. Previously collected ground data consisted of United States Forest Service (USDA FS) stand exams from 2008 and current vegetation survey (CVS) plots measured between 1998 and 2007 (US Forest Service). The stand exams and CVS plots were grown forward to 2009 with the Forest Vegetation Software (FVS) for the Blue Mountain region (Keyser \& Dixon, 2008). Eight additional cluster plots were measured during the summer of 2009 (Table 1).

The USDA FS stand exam data consist of 98 plots that were measured in the summer of 2008. Stand Exam plots are a nested plot design that consists of a variable radius plot for large trees and fixed radius plots for small trees and seedlings. A professional forester from the USDA FS went back and re-measured the plot so that a $1 / 10^{\text {th }}$ acre fixed plot was used for the large trees, instead of the previously measured variable radius plot design. These data were analyzed internally by the Forest Service within their plot compiler.
Table 1.

Number of plots in Damon site.

\begin{tabular}{cc}
\hline Source & Number of Plots \\
\hline USFS Current Vegetation System & 10 \\
USFS Stand Exams & 98 \\
Summer 2009 & 8 \\
\hline
\end{tabular}

CVS plot data were supplied by the USDA FS. CVS are permanent forest inventory plots in Region 6 (Pacific Northwest) of the USDA FS. Each plot is re-measured once every ten years. Within this study site, CVS plots are on a 1.7 mile systematic grid. The plots consist of a 2.47-acre circular plot with 5 sub-plots. Each sub-plot is a set of 3 plots: 1) 1/5.3-acre plot, 2) 1/24-acre plot, and 3) 1/100-acre plot. Each plot has set criteria for which data should be collected and recorded, including live and dead tree measurements, down woody debris, shrub and understory components, and general geographical and slope position information of the plot (US Forest Service, 2001).

Recent research has shown that stratifying the landscape using LiDAR data is an efficient and effective way to group the landscape into similar forest type and structure for further analysis (Sullivan, 2008; Koch et al., 2009; Mustonen et al., 2008). Accordingly, forested stands were delineated using differences in height and canopy closure characteristics. Percent canopy closure, $25^{\text {th }}$ and $75^{\text {th }}$ height percentiles were used following the process outlined by Sullivan (2008), stand delineations were created using two software packages, FUSION (McGaughey, 2009) and Spring (Câmara et al., 1996). The latter is a userbased classification software package. For this study, the stand density index (SDI) of forest service stand exam plots measured in 2006 was used for the training data of the user-based classification process.

The 8 cluster plots measured during the summer of 2009 consisted of a linear cluster (CLUS) of plots of four rectangular fixed radius subplots. Moisen et al. (1994) showed that linear clusters of plots was a cost efficient way of distributing forest inventory plots for assessing map accuracy, while accounting for spatial autocorrelation. The advantage of using a CLUS design is less cost in traveling to each plot as compared to a random design, while the disadvantage for CLUS is that there is more potential for spatial autocorrelation. Due to availability of previously collected inventory data we opted to use the cluster design to sample more ground area with our limited resources without sacrificing the total number of plot estimates. Our linear clusters consisted of four 1/10-acre rectangular fixed area plots. In order to assure a random sample, a grid of $1 / 10$-acre plots was placed over the project area and a random location was selected based on the plot allocation information previously computed. The other three plots were located by obtaining a random azimuth in one of the four cardinal directions, from the first plot center, and installing the three additional plots in a linear fashion.

Each tree in a plot was measured for diameter-at-breast height (DBH), species, and crown dominance (dominant, co-dominant, intermediate, or over-topped). A tree was measured if it was 4.5 feet tall or larger. The first, third and fifth tree per species per plot were measured for height, crown diameter, and crown ratio. Crown diameter was measured by taking a random azimuth and measuring the diameter of the crown at 
that azimuth, then taking the diameter of the crown perpendicular to the first measurement and averaging the two. Dead trees and snags, greater than five inches DBH were measured for $\mathrm{DBH}$ and height. All trees with broken tops were measured for height.

Ground data were collected on a TDS Ranger handheld computer, with the USDA FS Stand Exam software. Missing heights were estimated with localized height-diameter equations for the Blue Mountains as described in stand exam protocols (USDA FS, 2001).

\section{Data Compilation}

Total standing tree woody biomass (tons per acre) was estimated for each ground inventory plot. In this study, standing tree woody biomass is defined as the biomass of the bole, bark, and branches of the all standing dead and live trees that are greater than or equal to 4.5 feet tall. Volume and biomass estimates were calculated using the USDA FS Forest Inventory Analysis (FIA) equations cubic volume, including top and stump, and biomass equations for the Blue Mountains (US DA FS 2001). All results found in this study assume that the USDA FS FIA equations are true and that the underlying assumptions of the volume and biomass models are applicable to this study area.

LiDAR data were processed with FUSION (McGaughey, 2009). Raw LiDAR data files were clipped to each individual ground inventory plot and attributes such as a digital elevation model (DEM), height percentiles, and their variances were obtained. Additionally, using the GridMetrics batch processing tool these same estimates were obtained for all other areas within the study area. Percent cover, percent slope, aspect, and elevation of each plot were found using the LiDAR derived DEM.

Landsat Thematic Mapper (TM) data was downloaded from the United States Geological Survey Global Visualization (GloVis) website for the entire project area. The normalized difference vegetation index (ndvi) was calculated using bands three and four.

Climate data from the DAYMET website (Thornton, 2003) was downloaded for the entire project area. Variables of interest consisted of: average daily maximum temperature, average daily minimum temperature, average temperature, number of growing degree days, number of frost days, and total precipitation. All variables were merged into one large table on a $20 \times$ 20 meter pixel grid. Additionally, each of the ground inventory plots was added as separate rows to the table.

\section{Statistical Analysis}

For this study, explanatory variables were determined for the nearest neighbor imputations and geographic weighted regression, by implementing an all subsets stepwise regression technique, as outlined by Goerndt et al. (2010), using the regsubsets() function within the leaps package ( $\mathrm{R}$ Development Core Team, 2011). This tool returns the best fitting linear models according to the Bayesian information criteria (BIC).

Using the eight independent variables found by the best fitting linear model, a geographic weighted regression (GWR) model was fit using the $g w r$ tool within the spgwr R-package. Before a back transformation of the natural log biomass estimate was performed, a bias-correction factor of 0.5 times the mean square error was added to the estimates (Baskerville,
1972; Goerndt et al., 2010). Most similar neighbor (MSN), gradient nearest neighbor (GNN), k-nearest neighbor (k-MSN), and random forest (RF) were performed using the yai and impute tools within the yaImpute (Crookston \& Finley, 2008) R-package.

Each model was assessed using the 116 plots located within the study area. We used root mean square error (RMSE) and bias to evaluate the models. These values were estimated using a leave one out plot cross-validation. The root mean square error (Equation (1)) and bias (Equation (2)) were calculated using the following:

$$
\begin{aligned}
& \text { RMSE }=\sqrt{\frac{\sum_{i=1}^{n}\left(Y_{i}-\hat{Y}_{i}\right)^{2}}{n},} \\
& \text { bias }=\frac{\sum_{i=1}^{n}\left(Y_{i}-\hat{Y}_{i}\right)}{n},
\end{aligned}
$$

where $Y_{\mathrm{i}}$ is the observed value, $\hat{Y}_{i}$ is the imputed estimate, and $\mathrm{n}$ is the sample size (number of plots).

\section{Results}

The best linear model, for estimating biomass (tons per acre) on a plot included the following explanatory variables: the minimum value from the LiDAR height percentile profile (Min_Elev), $80^{\text {th }}$ percentile value of the height profile from the LiDAR data (P80), the longitudinal location of the plot (UTM_Y), the reflective property value of Landsat TM band 2 (LandsatB2), Normalized Difference Vegetation Index (ndvi), 18-year average daily minimum temperature (MinTemp), 18-year average of the number of growing degree days (DegDay), and the 18-year average of the annual precipitation (TotPrecip). The results of this linear model can be seen in Table 2.

The best fitting linear model, for estimating basal area per acre included the following variables: the standard deviation of all LiDAR returns on the plot (StdDev), the $95^{\text {th }}$ percentile value of the height profile from the LiDAR data (P95), and the reflective property value from Landsat TM band 5 (LandsatB5). The results from this linear model can be seen in Table 3 .

The inventory plots ranged in cover type, from non-forest meadows, to highly dense pine forests. Biomass measured on the inventory plots ranged from zero tons per acre to 103.7 tons per acre, with a standard deviation of 15.9 tons per acre. The basal area of the inventory plots ranged from zero square feet per acre to 248.7 square feet per acre, with a standard deviation of 55.6 square feet per acre (Table 4).

Nearest neighbor imputations rely on explanatory variables being correlated with the response variables. Thus, the higher the correlation coefficient the better the imputation model should perform. The highest correlation between the predictor variables and biomass per acre comes from the LiDAR derived P80 variable, a correlation coefficient of 0.44 (Table 5).

The highest coefficient in the basal area prediction methods was the P95 variable, correlation coefficient of 0.69 (Table 6).

The RMSE and bias for the nearest neighbor and OLS regressions for biomass (tons per acre) and basal area (square feet per acre) models are reported in Tables 7 and 8 , respectively.

For the biomass prediction, the k-MSN, $k=5$, has the lowest RMSE and least amount of bias. The second most accurate method consisted of the k-MSN, $k=3$, followed by the GWR 


\section{GAGLIASSO ET AL.}

model and the RF imputation. The GNN method was the least accurate (Table 7). For basal area prediction, the GWR model has the lowest RMSE and the least amount of bias. The second most accurate method was $\mathrm{k}-\mathrm{MSN}, \mathrm{k}=5$, followed by the $\mathrm{k}-\mathrm{MSN}, \mathrm{k}=3$ and then random forest. The GNN method was again the least accurate (Table 8).

Table 2.

Coefficients and standard errors for linear regression model for $\ln$ (biomass) in tons per acre.

\begin{tabular}{ccc}
\hline 80th percentile value from the LiDAR height profile & 0.0525 & 0.0165 \\
\hline UTM northing & -0.0003 & 0.0000 \\
Reflective property of Landsat TM band 2 & -0.1705 & 0.0411 \\
Normalized Difference Vegetation Index & -6.382 & 1.359 \\
18 year average of the daily minimum temperature & 5.052 & 0.2276 \\
18 year average of the number of growing degree days & 0.0329 & 0.0049 \\
18 year average of the annual precipitation & 1.231 & 0.1741 \\
\hline
\end{tabular}

Table 3.

Coefficient and standard errors for linear regression model for basal area ( $\mathrm{ft}^{2}$ per acre).

\begin{tabular}{ccc}
\hline Variable & Coefficient & SE \\
\hline Intercept & 50.12 & 22.32 \\
Standard deviation of all LiDAR returns on the plot & -27.79 & 5.212 \\
95th percentile value from the LiDAR height profile & 11.88 & 1.634 \\
Reflective property of Landsat TM band 5 & -0.7082 & 0.1908 \\
\hline
\end{tabular}

Table 4.

Basic statistics of explanatory and response variables ${ }^{1}$.

\begin{tabular}{|c|c|c|c|c|c|c|c|c|}
\hline \multicolumn{9}{|c|}{ Biomass (tons per acre) Explanatory variables } \\
\hline units & $\begin{array}{l}\text { Min_Elev } \\
\text { meters }\end{array}$ & P80 meters & UTM_Y & LandsatB2 $\mu \mathrm{m}$ & ndvi & $\begin{array}{l}\text { MinTemp } \\
\text { celsius }\end{array}$ & $\begin{array}{l}\text { DegDay } \\
\text { degree days }\end{array}$ & TotPrecip cm \\
\hline Minimum & 1.00 & 0.00 & 4882625.7 & 23.0 & 0.2 & -4.2 & 1895.7 & 46.2 \\
\hline Maximum & 4.42 & 33.9 & 4901661.6 & 39.0 & 0.7 & -2.2 & 2541.2 & 64.5 \\
\hline Mean & 1.14 & 14.5 & 4890903.5 & 27.8 & 0.4 & -2.9 & 2298.9 & 54.0 \\
\hline Median & 1.02 & 14.8 & 4888069.0 & 27.0 & 0.4 & -2.8 & 2312.5 & 53.9 \\
\hline \multirow[t]{8}{*}{ Standard Deviation } & 0.38 & 6.34 & 6759.8 & 3.5 & 0.1 & 0.5 & 168.0 & 4.2 \\
\hline & & & & \multicolumn{5}{|c|}{ Basal Area Explanatory Variables } \\
\hline & & units & $\begin{array}{l}\text { Biomass } \\
\text { tons per acre }\end{array}$ & $\begin{array}{l}\text { Basal Area square } \\
\text { feet per acre }\end{array}$ & StdDev meters & P95 meters & LandsatB5 $\mu \mathrm{m}$ & \\
\hline & & Minimum & 0.0 & 0.0 & 0.0 & 0.0 & 47.0 & \\
\hline & & Maximum & 103.7 & 248.7 & 13.6 & 42.6 & 134.0 & \\
\hline & & Mean & 8.9 & 79.3 & 4.7 & 18.2 & 80.0 & \\
\hline & & Median & 2.9 & 77.1 & 4.4 & 18.2 & 75.0 & \\
\hline & & $\begin{array}{l}\text { Standard } \\
\text { Deviation }\end{array}$ & 15.9 & 55.6 & 2.3 & 7.7 & 19.8 & \\
\hline
\end{tabular}

${ }^{1}$ Min_Elev = Minimum value of the LiDAR percentile height profile. $\mathrm{P} 80=80^{\text {th }}$ percentile of the LiDAR height profile. UTM_Y $=$ UTM northing coordinate. LandsatB2 $=$ reflective property of Landsat TM band 2 . Ndvi = normalized difference vegetation index. MinTemp $=18$-year average of the minimum temperature. DegDay $=18$ year average of the number of degree days. TotPrecip $=18$-year average of the annual precipitation. StdDev $=$ standard deviation of all LiDAR values on the plot. P95 $=95^{\text {th }}$ percentile of the LiDAR height profile. LandsatB5 = reflective property of Landsat TM band 5. 
Table 5.

Correlation coefficients of biomass vs. selected predictor variables ${ }^{2}$.

\begin{tabular}{|c|c|c|c|c|c|c|c|c|c|}
\hline & ln_Biomass & ln_BA & Min_Elev & P80 & UTM_Y & LandsatB2 & ndvi & MinTemp & DegDay \\
\hline ln_BA & 0.4339 & & & & & & & & \\
\hline Min_Elev & -0.2310 & -0.0870 & & & & & & & \\
\hline P80 & 0.4368 & 0.5303 & -0.0827 & & & & & & \\
\hline UTM_Y & -0.3135 & -0.1858 & 0.1243 & -0.2442 & & & & & \\
\hline LandsatB2 & -0.3320 & -0.4832 & 0.1873 & -0.5834 & 0.4484 & & & & \\
\hline ndvi & -0.0516 & 0.1673 & -0.0568 & 0.3494 & -0.0614 & -0.5555 & & & \\
\hline MinTemp & 0.0321 & -0.0374 & 0.2089 & -0.0473 & 0.4424 & 0.2309 & -0.2012 & & \\
\hline DegDay & -0.1544 & -0.0488 & 0.1485 & -0.1336 & 0.4563 & 0.1331 & -0.1158 & 0.5835 & \\
\hline TotPrecip & 0.1158 & -0.0064 & -0.1164 & 0.0742 & -0.1848 & 0.0158 & 0.1085 & -0.4904 & -0.9529 \\
\hline
\end{tabular}

${ }^{2}$ Min_Elev $=$ Minimum value of the LiDAR percentile height profile. $\mathrm{P} 80=80^{\text {th }}$ percentile of the LiDAR height profile. UTM_Y $=$ UTM northing coordinate. LandsatB2 $=$ reflective property of Landsat TM band 2 . Ndvi = normalized difference vegetation index. MinTemp $=18$-year average of the minimum temperature. DegDay $=18$ year average of the number of degree days. TotPrecip $=18$-year average of the annual precipitation.

Table 6.

Correlation Coefficients of basal area vs. selected predictor variables.

\begin{tabular}{|c|c|c|c|c|}
\hline & Biomass per acre & Basal area per acre & $\begin{array}{l}\text { Standard Deviation of } \\
\text { LiDAR returns }\end{array}$ & $\begin{array}{l}\text { 95th percentile value of } \\
\text { LiDAR height profile }\end{array}$ \\
\hline Basal area per acre & 0.4372 & & & \\
\hline Standard Deviation of LiDAR returns & 0.1691 & 0.5749 & & \\
\hline $\begin{array}{l}\text { 95th percentile value of } \\
\text { LiDAR height profile }\end{array}$ & 0.1883 & 0.6870 & 0.9651 & \\
\hline $\begin{array}{l}\text { Reflective property of } \\
\text { Landsat TM band } 5\end{array}$ & -0.2282 & -0.6225 & -0.4757 & -0.5477 \\
\hline
\end{tabular}

Table 7.

RMSE and bias for estimating biomass (tons/acre) by selected method.

\begin{tabular}{ccc}
\hline Model & RMSE & Bias \\
\hline Linear regression & 12.7 & -2.41 \\
Geographic Weighted Regression & 11.6 & -0.67 \\
Gradient Nearest Neighbor & 16.31 & -0.008 \\
Most Similar Neighbor & 13.96 & -0.08 \\
Random Forest & 12.22 & -1.87 \\
k-MSN $(\mathrm{k}=3)$ & 11.53 & 0.24 \\
k-MSN $(\mathrm{k}=5)$ & 11.24 & -0.004 \\
\hline
\end{tabular}

\section{Discussion}

Substantial differences were found among the predictive abilities of the strategies examined to predict forest biomass and basal area. As a result, the seemingly divergent parametric and non-parametric approaches resulted in different predictions. GWR outperformed the other methods in terms of accuracy and precision when predicting basal area per acre. This might be ascribed to GWR's ability to localize the relation between the response variable and covariate in both the geographical and feature and variable space.
Table 8.

RMSE and bias for estimating basal area ( $\left.\mathrm{ft}^{2} / \mathrm{acre}\right)$ by selected method.

\begin{tabular}{ccc}
\hline Model & RMSE & Bias \\
\hline Linear regression & 33.15 & 0.0029 \\
Geographic Weighted Regression & 33.08 & 0.0082 \\
Gradient Nearest Neighbor & 58.65 & -4.79 \\
Most Similar Neighbor & 50.99 & 0.13 \\
Random Forest & 39.03 & 2.82 \\
k-MSN $(\mathrm{k}=3)$ & 39.02 & 0.67 \\
k-MSN $(\mathrm{k}=5)$ & 38.62 & 0.71 \\
\hline
\end{tabular}

Possible reasons for GNN performing poorly, compared to the other methods, include the small size of the project site compared to previous uses of the GNN method (Ohmann \& Gregory, 2002) and the explanatory variables' lack of high correlation with the response variables. The GWR method may perform better than the non-parametric approaches due to only predicting one response variable, biomass. In contrast, the nearest neighbor methods are predicting both biomass and basal area simultaneously. Therefore, GWR may be sufficient for the estimation of biomass per acre if that is the only variable of interest; while, the nearest neighbor imputations are preferred 
when multiple response variables of interest are present in the analysis. When predicting a single variable, Eskelson et al. (2009b) reported that parametric methods resulted in better performance than non-parametric methods.

The results of this study suggest that the current method being used to implement forest management activities on the Malheur National Forest, MSN, may not be the best method to predict total standing tree woody biomass. Instead, the k-MSN or RF method may be preferable, particularly if multiple response variables are important to consider. In contrast, if users are only interested in a single response variable, total standing tree biomass, GWR appears more suitable.

\section{REFERENCES}

Baskerville, G. L. (1972). Use of logarithmic regression in the estimation of plant biomass. Canadian Journal of Forestry, 2, 49-53. http://dx.doi.org/10.1139/x72-009

Câmara, G., Souza, R., Freitas, U., \& Garrido, J. (1996). SPRING: Integrating remote sensing and GIS by object-oriented data modeling. Computers and Graphics, 20, 395-403. http://dx.doi.org/10.1016/0097-8493(96)00008-8

Crookston, N. L., \& Finley, A. O. (2008). yaImpute: An R package for kNN imputation. Journal of Statistical Software, 23, 1-16.

Crow, T. R., \& Schlaegel, B. E. (1988). A guide to using regression Equations for estimating tree biomass. Northern Journal of Applied Forestry, 5, 15-22.

Eskelson, B. N. I., Temesgen, H., \& Barrett, T. M. (2009a). Estimating current forest attributes from paneled inventory data using plot-level imputation: A study from the Pacific Northwest. Forest Science, 5, 64-71.

Eskelson, B. N. I., Temesgen, H., \& Barrett, T. M. (2009b). Estimating cavity tree and snag abundance using negative binomial regression models and nearest neighbor imputation methods. Canadian Journal of Forest Research, 39, 1749-1765. http://dx.doi.org/10.1139/X09-086

Fotheringham, A. S., Brunsdon, C., \& Charlton, M. (2002). Geographically weighted regression: The analysis of spatially varying relationships. Chichester, Hoboken, NJ: Wiley.

Goerndt, M. E., Monleon, V. J., \& Temesgen, H. (2010). Relating forest attributes with area- and tree-based light detection and ranging metrics for Western Oregon. Western Journal of Applied Forestry, 25, 105-111.

Hudak, A. T., Crookston, N. L., Evans, J. S., Hall, D. E., \& Falkowski, M. J. (2008). Nearest neighbor imputation of species-level, plot-scale forest structure attributes from LiDAR data. Remote Sensing of Environment, 112, 2232-2245. Corrigendum: (2009). Remote Sensing of Environment, 113, 289-290.

http://dx.doi.org/10.1016/j.rse.2008.08.006

Hummel, S., Hudak, A. T., Uebler, E. H., Falkowski, M. J., \& Megown, K. A. (2011). A comparison of accuracy and cost of LiDAR versus stand exam data for landscape management on the Malheur National Forest. Journal of Forestry, 109, 267-273.

Keyser, C. E., \& Dixon, G. E. (2008). Blue Mountains (BM) variant overview-Forest vegetation simulator. Internal Rep., Fort Collins, CO: US Department of Agriculture, Forest Service, Forest Management Service Center. (revised February 3, 2010)

Koch, B., Straub, C., Dees, M., Wang, Y., \& Weinacker, H. (2009). Airborne laser data for stand delineation and information extraction. International Journal of Remote Sensing, 30, 935-963. http://dx.doi.org/10.1080/01431160802395284

Maltamo, M., Malinen, J., Packalén, P., Suvanto, A., \& Kangas, J. (2006). Nonparametric estimation of stem volume using airborne laser scanning, aerial photography, and stand-register data. Canadian Journal of Forest Research, 36, 426-436. http://dx.doi.org/10.1139/x05-246

McGaughey, R. J. (2009). FUSION/LDV: Software for LIDAR data analysis and visualization, Version 2.9. USDA FS.

http://www.fs.fed.us/eng/rsac/fusion/

Moeur, M., \& Stage, A. R. (1995). Most similar neighbor: An improved sampling inference procedure for natural resource planning. Forest Science, 41, 337-359.

Moisen, G. G., Edwards Jr., T. C., \& Cutler, D. R. (1994). Spatial sampling to assess classification accuracy of remotely sensed data. In J. Brunt, S. S. Stafford, \& W. K. Michener (Eds.), Environmental information management and analysis: Ecosystem to global scales (pp. 161-178). Philadelphia, PA: Taylor and Francis.

Mustonen, J., Packalén, P., \& Kangas, A. (2008). Automatic segmentation of forest stands using canopy height model and aerial photograph. Scandinavian Journal of Forest Research, 23, 534-545. http://dx.doi.org/10.1080/02827580802552446

Ohmann, J. L., \& Gregory, M. J. (2002). Predictive mapping of forest composition and structure with direct gradient analysis and nearestneighbor imputation in coastal Oregon, U.S.A. Canadian Journal of Forest Research, 32, 725-741. http://dx.doi.org/10.1139/x02-011

Næsset, E. (2004). Accuracy of forest inventory using airborne laser scanning: Evaluating the first Nordic full-scale operation project. Scandinavian Journal of Forest Research, 19, 554-557. http://dx.doi.org/10.1080/02827580410019544

Nelson, R., Short, A., \& Valenti, M. (2004). Measuring biomass and carbon in Delaware using an airborne profiling LiDAR. Scandinavian Journal of Forest Research, 19, 500-511. http://dx.doi.org/10.1080/02827580410019508

$\mathrm{R}$ Development Core Team (2011). R: A language and environment for statistical computing. Vienna: R Foundation for Statistical Computing. http://www.R-project.org/

Salas, C., Ene, L., Gregoire, T. G., Næsset, E., \& Gobakken, T. (2010). Modelling tree diameter from airborne laser scanning derived variables: A comparison of spatial statistical models. Remote Sensing of Environment, 114, 1277-1285. http://dx.doi.org/10.1016/j.rse.2010.01.020

Sullivan, A. (2008). LIDAR based delineation in forest stands. Master's Thesis, Seattle, WA: University of Washington.

Temesgen, H., LeMay, V. M., Marshall, P. L., \& Froese, K. (2003). Imputing tree-lists from aerial attributes for complex stands of south-eastern British Columbia. Forest Ecology and Management, 177, 277-285. http://dx.doi.org/10.1016/S0378-1127(02)00321-3

Thornton, P. E. (2003). DAYMET climatological summaries for average air temperature and total precipitation (18-year mean for 19801997). Missoula, MT: University of Montana, Numerical Terradynamic Simulation Group. http://www.daymet.org

US Forest Service (2001). Region 6 inventory \& monitoring system: Field procedures for the current vegetation survey. Natural Resource Inventory, Pacific Northwest Region. Version 2.04, Portland, OR: USDA Forest Service.

Wang, Q., Ni, J., \& Tenhunen, J. (2005). Application of a geographically-weighted regression analysis to estimate net primary production of Chinese forest ecosystems. Global Ecology and Biogeography, 14, 379-393. http://dx.doi.org/10.1111/j.1466-822X.2005.00153.X

Wulder, M. A., Bater, C. W., Coops, N. C., Hiker, T., \& White, J. C. (2008). The role of LiDAR in sustainable forest management. The Forestry Chronicle, 84, 807-826. 